\title{
Waka Oranga: The Development of an Indigenous Professional Organisation within a Psychotherapeutic Discourse in Aotearoa New Zealand
}

\author{
Alayne Mikahere-Hall (Ngāti Whātua, Te Rarawa, Tainui), \\ Margaret Poutu Morice (Ngāti Porou), \\ Cherry Pye (Ngāti Ranginui)
}

Waka Oranga, Auckland, Hawke’s Bay, Tauranga, Aotearoa New Zealand

\section{Whakarāpopotonga}

E matapakihia ana e tēnei pepa te whakanaketanga i Aotearoa nei o tētahi rōpū pīpì ngaio Māori, a Waka Oranga, e warea nei ki te: whakaū hauora taketake, taituara hauora hinengaro ki ngā whānau Māori taka ki roto i te wheako kōmingomingo, tiwhatiwha hoki; me te hoatu ārahi, mātanga hāpai ki ngā mātanga Iwi-kē. Ka whakaurua e te pepa te whanaketanga nei ki rō āhuatanga, ka matapakihia te àta o te īngoa o te rōpū me tōna waitohu, whakarāpopotohia te anga o tōna hanga, ōna uara, āna hātepe, ka whakatutuki ai ki āna mātāpono me ōna pōhewa.

\section{Abstract}

This article discusses the development in Aotearoa New Zealand of a fledgling Māori professional organisation, Waka Oranga, which is engaged in providing Indigenous healing and psychotherapeutic support to Māori families who experience trauma and discontent in their lives, and supervision and consultancy to Māori and non-Māori professionals. The article sets this development in context, discusses the symbolism of the organisation's name and logo, summarises its organisational structure, values and processes, and concludes with its principles and vision.

Key words: Waka Oranga; Māori; Indigenous; culture; health; values

Originally published in Psychotherapy and Politics International, 10(1), 7-16. https://doi. org/10.1002/ppi.1255. Copyright (C) 2012 John Wiley \& Sons, Ltd. Reproduced with the kind permission of Wiley Inc.

\footnotetext{
Mikahere-Hall, A., Morice, M. P., Pye, C. (2019). Waka Oranga: The development of an Indigenous professional organisation within a psychotherapeutic discourse in Aotearoa New Zealand. Ata: Journal of Psychotherapy Aotearoa New Zealand, 23(1), 23-34. https://doi.org/10.9791/ajpanz.2019.04
} 


\section{Introduction}

In Aotearoa New Zealand Māori are recognised as tāngata whenua, the indigenous people of the land. (New Zealand born non-indigenous people are generally referred to as Pākehā; and the term tau iwi distinguishes more recent immigrant peoples from New Zealand Pākehā). As with most Indigenous peoples and cultures, Māori have not fared well through colonisation, with its resultant social injustices and structural inequities, and the imposition and assumption of Western ways, including psychotherapy. Undeterred, Māori have remained steadfast in our attempts to strive for good health, education and economic advancement, and we continue to make major contributions in these sectors in mitigating existing inequalities.

All contemporary Mãori health perspectives seek to widen understandings of health, to translate health into terms which are culturally relevant and significant, and to balance the Western medical model with an awareness of social and cultural factors. The particular contribution of models of health that invoke Māori traditional values and belief systems is their ability to help us recover from an excessively narrow focus on illness and individual pathology, and to restore us to a more balanced and holistic perspective on wellness (see Durie, 1999). From a kaupapa Māori perspective, the medical model assumes that health is one and the same thing for all people, and fails to recognise the degree to which cultural factors are crucial to the development and maintenance of good health. The development of Māori psychotherapy has several different aspects. These include the development of Māori practice; for example, kaupapa Māori theory and practice, the development of Māori practitioners through the recognition and development of Māori training programmes and practitioner networks, and the development of cultural competencies specific to Aotearoa New Zealand for both Māori and non-Māori (Morice, 2003; Morice \& Woodard, 2011).

\section{Waka Oranga}

The sea-ferrying craft which transported the migrating Polynesian inhabitants through the South Pacific Seas to arrive on the shores of Aotearoa were known as waka. They were large double-hulled sailing canoes sturdy enough to encounter the unknown vastness beyond the horizons and equipped with necessities considered essential for such a voyage. As evidenced by carbon dating and known through oral histories (Wilmshurst, Anderson, Higham, \& Worthy, 2008), the islands of Aotearoa New Zealand were inhabited by Māori as far back as the 12th century. Waka means canoe or canoes, which can range in size depending on the purpose for which they are constructed and, like our ancestors before us, Māori continue to carve out and recreate waka for both ceremonial and practical purposes. Māori maintain the tradition of identifying with the migratory waka of their ancestors, from which many confederations of tribes were formed. Waka were the transportation vessels used to carry both our ancestors and their dreams and aspirations across new frontiers for the hope of a better future; similarly, this word in the title of our organisation carries both us and our aspirations for increased consciousness and more appropriate healing practices. The word "oranga" is linked to the word "ora" which, in essence, describes a state of health and wellbeing. Oranga is about survival, livelihood, welfare and all the necessary determinants required to achieve a healthy sense of "ora". The term can be heard in everyday Māori 
conversation: at the point of first contact, one might greet and acknowledge another with the words "kia ora". This greeting is often translated as "Hello"; its deeper meaning, however, conveys and bestows the sentiment of good health (Hall, 2011).

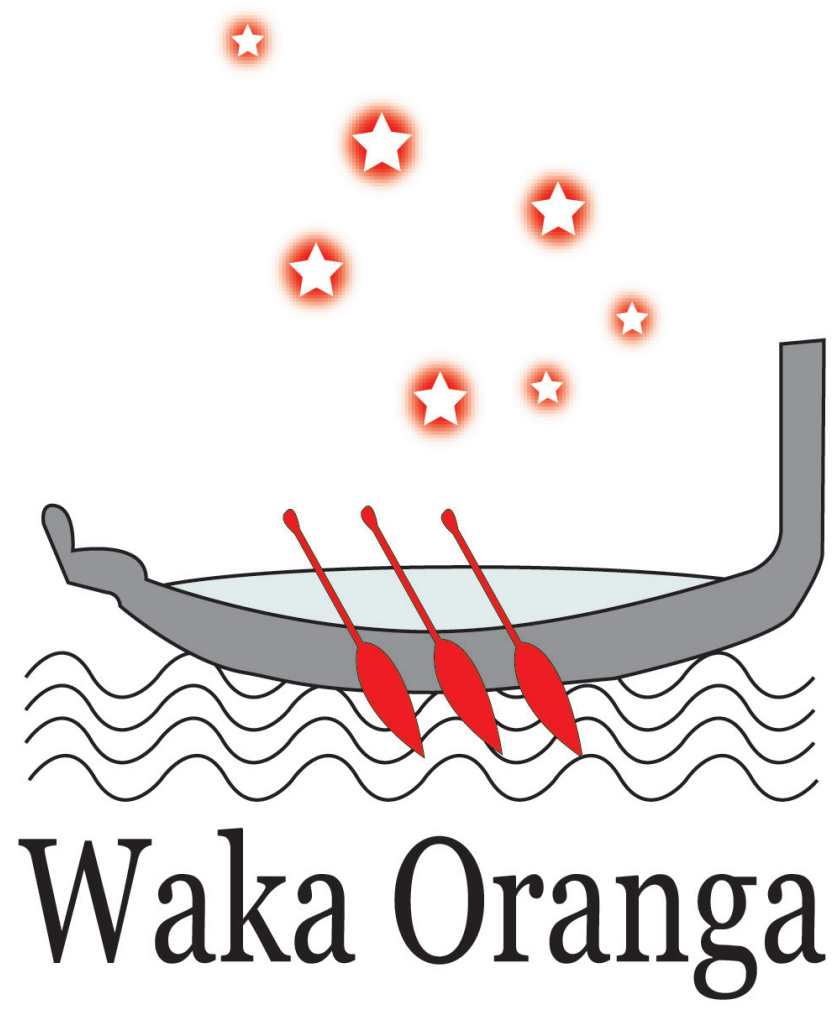

FIGURE 1

\section{Our Logo and Its Symbolism}

To understand better the functioning of Waka Oranga, it is useful to examine the symbolic meaning of our logo and how this represents who we are and what we do (Figure 1). Firstly, we pay homage to our ancestors, and they are represented by and are imbued in all the aspects of our logo: the heavens, the water, the canoe, and the paddles. Our ancestors are omnipresent, and we are inspired and guided by their enduring spirits and, indeed, it is common Māori practice to seek direct guidance and intervention from our tūpuna (ancestors).We, in turn, are responsible to them: to carry on where they left off. We, as Māori psychotherapists and Indigenous practitioners, have chosen or have been chosen to work in the healing field, and there is an expectation that we do this to help our people.Acknowledging tūpuna and reciting whakapapa (genealogy) are fundamental to our identity and who we are. The unoccupied space within the waka represents the potentiality for people to come on board and share our vision and aspirations. From a Māori philosophical world view, elders 
are afforded a special place. As is common practice within a Māori world view, our name, Waka Oranga, was gifted to us by an elder. In this instance, it was our kaumatua or elder, Haare Williams. Haare is well respected in the Māori world, and has had a long relationship with the New Zealand Association of Psychotherapists (NZAP) as a cultural advisor. From our conception over the past five years, Haare has provided guidance, leadership and mentorship, and instils us with traditional Māori values through his teachings. The logo was created to incorporate and give expression to the significant aspects of our name. It comprises four primary elements: the star constellation Matariki (Pleiades); a waka; three hoe (paddles); and the moana (sea). All are necessary components for the well-being of those who occupy the waka.

\section{Matariki (Pleiades): The heavens}

For Māori, the appearance of Matariki in early June represents the new year: a time of renewal, and a time to gather and to reflect on the past and the future. Matariki has two meanings, both of which refer to a tiny constellation of stars: Mata Riki (Tiny Eyes) and Mata Ariki (Eyes of God). Stars were - and still are - used by Māori as a way to calculate time and seasons, navigate oceans, preserve knowledge and stories, maintain customary practices, and inspire action and achievement. Māori organise knowledge in two ways: te kauae runga (upper knowledge or celestial knowledge), and te kauae raro (lower knowledge or earthly knowledge). Matariki (Pleiades) sits in the realm of both the cosmos and the heavens and the tiny constellation of stars we know as Matariki reminds us to seek wisdom and knowledge for the benefit of others from the highest sources.

\section{Te moana: The sea}

As in many cultures that rely on the sea, for Māori the moana is the food basket which has fed the multitudes throughout the centuries. On one level, the symbolic representation of the sea is linked to the nourishment and sustainability required for good health and well-being; on another level, it also reminds us of the great courage and strength our ancestors had when they first set out across the vast expanse of the South Pacific Ocean. Moreover, as the sea connects with both the skies or the heavens above and the land beneath, it represents the fluidity between both conscious and subconscious states. The ever-changing currents, swells, calm and turbulent conditions of the moana keep us alert to the ebb and flow of our political and social environments, reminding us to keep the waka upright, balanced and on course.

\section{Te waka: The canoe}

The waka acts both as a container and a transporter. We - both Māori and our non-Māori associate and institutional members - are all committed and responsible for moving the waka. Some are pulling, some are paddling, some are resting on the shore, and some are way in the distance, guiding and urging us onward. Those who occupy the waka need two sets of skills: firstly, paddling skills to ensure that the waka remains afloat on the fluctuating waterways, streams, harbours and oceans it is destined to encounter; and, secondly, navigational skills to ensure that the waka remains on a course that will steer us toward a better future with all the provisions necessary to make this journey possible. 


\section{Ngā hoe: The paddles}

The first paddle represents our elders. They are our esteemed leaders. We have a kaumatua (male elder), Haare Williams, and a kuia (female elder), Hinewirangi Kohu-Morgan. Both are actively involved with us: they guide, instruct, and educate us by way of incantation and prayer, by sharing knowledge, by song, and sometimes by reprimand when we get it wrong. They point the way forward and remind us of where we have come from.

The second paddle in the waka represents the runanga (council/committee/board). The runanga refers to the governance council members, which comprises the founding associates of Waka Oranga and representatives appointed by consensus at the Annual General Meeting. In addition to the runanga members, the second paddle also represents the Indigenous members of Waka Oranga and their children.

The third paddle represents associate and institutional members. They are New Zealandborn or immigrant, non-Indigenous psychotherapists or healthcare providers who are not registered psychotherapists (for a discussion, see Morice \& Woodard, 2011; Tudor, 2011), and/or those who have an interest in developing cultural approaches to therapy. The majority of our members hold dual membership with Waka Oranga and the NZAP. Waka Oranga's relationship with the NZAP is a partnership based upon the principles of Te Tiriti o Waitangi (the Treaty of Waitangi), which is the founding document and unique agreement or arrangement between the Indigenous people of Aotearoa New Zealand and the (British) Crown (see Waitangi Tribunal, 2011). The Treaty provides the foundation for the political, economic, spiritual and social context of our work and our lives. The depth of commitment and level of financial support from NZAP need to be acknowledged for, without their efforts, we would indeed struggle. Occasional funding from other sources, along with membership subscriptions, enables us to continue to operate and evolve.

\section{Organisational Structure and Values}

Waka Oranga is a New Zealand registered incorporated society with non-profit charitable status. The organisation adheres to a number of legally binding and constituted principles which outline the core purposes of the society and detail the governing powers and proceedings of the society and its members. The membership comprises both Māori and non-Māori practitioners who predominantly have trained in the field of psychotherapy. All members of Waka Oranga are committed to developing a greater professional and community consciousness concerning the use of core relational and traditional Māori concepts that promote healing.

The philosophies that underpin Waka Oranga's constitution are based upon the belief and assertion that Indigenous knowledge and theory are valid and, therefore, we strive to uphold and honour Māori wisdom and values. Our Indigenous practitioners are all committed to upholding the tenets of our constitution, which embrace six core values considered essential in the delivery of clinically effective therapeutic practice and ethically sound practitioner conduct (see Morice, 2003). These values are: wairuatanga, manaakitanga, whanaungatanga, kaitiakitanga, kotahitanga and rangatiratanga. 


\section{Wairuatanga}

Wairuatanga acknowledges the spiritual essences of a person's unique being and the source of all life form through atua (gods). A Māori belief system supports a view that all living things on Earth and within the universe including stars and planets were created and that "atua are the gods responsible for this creation" (Barlow, 1994, p. 11). Wairuatanga is taken from the word "wairua", which literally translates as "two waters". Such translation, however, again does not reveal the depth of meaning of the word. Wairua refers to the connection between physical existence and spiritual existence and the flow of energy between these interwoven systems. Wairua and its principle, wairuatanga, are pivotal to Māori people and our perceptions of health and our connections with the physical world, i.e. people, mountains, rivers and places. Wairuatanga encourages our members to maintain and uphold our spiritual identity through a connectedness with each other and to our environments. Holding the principle of wairuatanga gives us the confidence to develop nourishing and nurturing relationships within our organisation and in our external relationships with whānau (family), hapū (sub-tribe(s)), iwi (tribe(s)) and networks within the national and international community. Thus Mãori psychotherapists recognise the transpersonal dimensions of human experiences and its importance to the process of healing and becoming integrated and whole.

\section{Manaakitanga}

Manaakitanga is concerned with the enactment of beliefs through sets of behaviour which express concern, generosity, hospitality, mutual respect, equality and humility. Manaakitanga acknowledges firstly that all things originate from atua and are therefore intrinsically connected to spiritual power. From this standpoint all things created by atua are inherited with "mana", which is an indestructible and spiritually derived form of charisma, agency and authenticity. It is through the experiences of our human development and sense of autonomy that we are able to enhance or diminish one's own sense of personal power and mana tangata (authority) through either action or inaction. One's own sense of mana is enhanced through the accumulation of compassionate acts of kindness, services to humanity and humility. Manaakitanga is mana in action, which acknowledges the mana of others as having equal authority, through spiritual inheritance or greater individual importance through acts of leadership and personal contribution to the welfare of others. Manaakitanga is founded on the recognition that when we uphold and elevate the mana of others, our own mana is upheld and elevated. When we are generous, respectful, hospitable, sensitive and receptive, we acknowledge others without diminishing ourselves. This serves the basic purpose of the psychotherapy relationship, which is to benefit the other, to assist clients to re-establish and strengthen themselves through self-understanding and the experience of being understood. Māori psychotherapy practitioners are encouraged to honour the concept of manaakitanga in all their actions and thoughts, offering their clients responsible care and mutual respect.

\section{Whanaungatanga}

Whanaungatanga is the principle that binds individuals to the wider group and affirms the value of the collective. Whanaungatanga is the extension of the basic whānau (family) social 
unit, which is expanded across a number of hapū and accumulated to form the foundations of a greater political grouping referred to as iwi. Whanaungatanga provides a social organisational kinship system where rights and obligations to each other are based on reciprocity for the overall well-being of the collective. Whanaungatanga affirms both the special and individual contributions and collective contributions members make to each other, the organisation, and the wider community. Whanaungatanga acknowledges the importance of people and recognises that our health, prosperity, well-being and aspirations rest within the collective wealth of people. Māori Indigenous psychotherapy practitioners are encouraged to honour the collective concept of whanaungatanga by maintaining supportive and healthy relationships in our approach to our work with people, in our organisational relationships and in our external relationships with other sector and community groups. Māori Indigenous psychotherapy practitioners affirm the crucial importance of relationships and particularly family relationships to all human development. We understand that psychological maturity is achieved through the capacity for interdependence as well as independence. In our contact with clients and others our members are encouraged to seek and maintain contact, connection, mutuality, reciprocity, and appropriate intimacy.

\section{Kaitiakitanga}

Kaitiakitanga is concerned with the responsibilities of actively exercising guardianship in a responsible manner to ensure sustainable futures and for the beneficial welfare of Māori Indigenous psychotherapy practitioners and the communities in which they work. Kaitiakitanga embraces the promotion of personal growth and professional development to advance the aspirations and desires of Mãori to fulfil our potential. Kaitiakitanga requires Māori practitioners to deliver services that support and advocate for the care and welfare of people within different environments. Kaitiakitanga is not limited to the development of individual or organisational goals; it also extends to the natural environment around us. Marsden (1992/2003) stated that "Man is the conscious mind of Mother Earth and plays a vital part in the regulation of her life support systems and man's duty is to enhance and sustain those systems" (p. 69). Māori Indigenous psychotherapy practitioners are encouraged to take responsible care of natural and human resources and act as caregivers for the intra-psychic world of our clients.

\section{Rangatiratanga}

Words within the Mãori language can have several meanings depending on the context in which they are used. Essentially, rangatiratanga means leadership; however, its root and associated words give this some nuance: from "ranga", meaning to rise up or to emancipate, "raranga" (to weave), and "tira", which refers to a group of people or stars. A person may be recognised and afforded the well-respected title of "rangatira" due to their personal attributes, which may include humility, leadership by example, caring regard for others, generosity, diplomacy, and specialist knowledge shared for the benefit of others. According to Morice and Woodard (2011), "A rangatira is a leader who weaves the people together" (p. 75). Rangatiratanga also recognises both an individual and the collective right to be selfdetermining in thought, feeling and behaviour, and to be liberated from injustices. Thus Māori Indigenous psychotherapy practitioners are encouraged to support the principles of 
sovereignty and self-determination for all persons and peoples. We also affirm that good authority demonstrates congruence, integrity and leadership by example.

\section{Kotahitanga}

Kotahitanga articulates unification and togetherness. Kotahitanga is motivated by the collective power of people to be purpose driven and, within this, to be unified. Kotahitanga is reflected when movement and transformational change occur through the achievement of consensus, balance and harmony. Kotahitanga should not be confused with uniformity or the production of identical views and opinions; it is, rather, about the achievement of shared aims, intentions and about moving as one, united through mutual understanding. Māori Indigenous psychotherapy practitioners are encouraged to help people interpret their lives and overcome the negative effects of domination and despair through unifying and integrating aspects of the splintered personality in the process of becoming whole.

\section{Organisational Processes and Community Relationships}

The runanga (governance committee) includes a chairperson, secretary and a treasurer. There is a minimum of five and a maximum of eight members. Each person on the runanga has a specific function to perform, in addition to implementing the general goals of the group. Two members of the runanga are elected to represent the interests of Waka Oranga and concerns related to Indigenous Māori psychotherapists on the NZAP Council. The runanga meets at least three or four times a year to attend to business matters and the continued development of the organisation. Proceedings at these meetings begin with greeting and connecting with each other, accompanied by prayer and song. As is the usual format of meetings, we address agenda items and general business. We usually stay together for several days, eating and sleeping alongside each other to get through our work. Our children are integral to who we are and how we conduct and organise ourselves, and wherever possible our children participate in attending our hui (meetings/gatherings). As a Māori organisation we operate within the conventions of a Māori whānau system, where the inclusion of children is fundamental. Appropriate caregivers are organised to attend to the children or "tuakana/teina" (older/ younger) relationships which are governed by whanaungatanga, whereby tuakana or older children in their late teens will take responsibility for the care of teina or the younger children, thereby freeing the parents to work on the organisational matters. We conclude our meetings with prayer, singing, and a summary of our time together.

We have an annual general meeting which the wider membership attends, and this takes place over three days. This is held on a marae, a place where Māori are able to express traditional rituals of encounter freely. We meet mainly in the wharenui, a big meeting house. Again, as we work through the programme, we all sleep alongside each other and eat together. This provides an intense setting in which we generally find we achieve what we need to do. We believe that whatever needs to be covered will be attended to, as we trust the setting implicitly as it is a place where we know we are protected and guided by both our elders and our ancestors.

As practitioners we work within a myriad of settings, which include community settings within our tribal homelands and in urban settings; in the public sector, for example, in hospitals, in the voluntary sector, in various agencies, and/or in private practice. Māori 
psychotherapy practitioners maintain a belief that the needs and rights of individuals are inseparable from the needs and rights of whānau, hapū, and iwi. This belief is supported by an appreciation for traditional knowledge concerning the interconnectedness and dynamic arrangement of a traditional Māori whānau system. The traditional and cultural imperatives of a Māori whānau system continue to operate while we adapt and evolve culturally through a dominant discourse, technological advancement and the economic drivers of globalisation (Hall \& Kohu-Morgan, 2011). Current trends in Māori household composition indicate that traditional family living arrangements and practices persist and, in terms of the population of Aotearoa New Zealand as a whole, Māori are more likely to be living in multi-family households; figures show that more than $90 \%$ of Māori live in multi-family arrangements (Statistics New Zealand, 2006). To the uninitiated psychotherapist or health care provider, the relationships between Māori families can be viewed as complex; however, Māori practitioners who are accustomed to cultural norms and practices are less likely to be overwhelmed by these complexities.

Waka Oranga aspires to achieve health and well-being both for our members and clients, and for whānau, hapū and iwi. These fundamental aspects of doing what is right in a Māori way involves kaitiakitanga, which is concerned with environmental guardianship and sustainability, social justice and spiritual fulfilment. We affirm that our intra-psychic reality is a microcosm and reflection of the worlds in which we live.

As Waka Oranga is a national organisation, we are dispersed throughout the various regions of Aotearoa New Zealand; all the Māori members in Waka Oranga come from different tribal affiliations and regions within the country and this presents as one of many challenges. For example, Māori psychotherapists and practitioners hold many sets of accountabilities which are professional and personal. We are also expected to participate in and engage in matters concerning our respective hapu and iwi, in and to which some of us hold greater responsibilities than others. Unlike our non-Māori colleagues, Māori Indigenous psychotherapists and practitioners are confronted on a daily basis with the reality of two sets of accountabilities: both to the Māori world and to the more dominant Western world.

Regardless of the various challenges, and wherever possible, the runanga members of Waka Oranga work towards meeting in a central location to enable greater access. Māori have a phrase, "kanohi ki te kanohi", which means "face-to-face". This is our preferred way of being with each other, and our budget is prioritised to preserve this. Our biggest expense is related to travel costs to attend meetings, and communication by e-mail, teleconference and/or Skype only goes part way to communicating with each other effectively. Being physically present, working, singing, praying, talking, and sharing food enables the fullness of each other to be appreciated.

\section{Waka Oranga’s Kaupapa: Founding Principles and Vision}

Our kaupapa (founding principles) express the philosophical underpinnings and aspirations of our organisation to include the following:

To honour atua, our people and our land.

To honour Te Tiriti o Waitangi in all our actions, thoughts and deeds. 
To uphold the Māori values and truths which are reflective of our kaupapa in our operational processes.

To be advocates for social justice and change in Aotearoa New Zealand.

To acknowledge the mana of all individuals and to act in a way that upholds the professional integrity both of our members and of Waka Oranga.

To be conscious and self-reflective of our own values and the values of others.

To acknowledge the diversity among Mãori in Aotearoa New Zealand.

To participate actively in the development of the whānau (extended family), hapu (subtribe) and iwi (tribe), both personally and professionally.

To promote actively the growth of an Indigenous psychotherapy that reflects our values, beliefs and practices.

To be committed to the development of professional practice through ongoing education, training, research, and networking.

To contribute professional expertise to the development of Indigenous psychotherapy policies, programmes and legislation that directly benefit whānau, hapū and iwi.

Membership of Waka Oranga is open to those who believe in our values and support our stated principles and goals.

\section{Conclusion}

Given its origins and history, psychotherapy as a concept and a practice is predominantly part of the Western intellectual tradition. As such, when exported to other cultures, it needs some acculturation if it is to avoid remaining monocultural. The need for a Māori psychotherapy is relatively obvious to anyone who is Māori. The purpose of a Māori psychotherapy is no different from the purpose of Pākehā psychotherapy for Pākehā or tau iwi. However, as long as psychotherapy remains monocultural, it will remain unable to meet the needs and aspirations of Māori practitioners and Māori clients. Thus, in and from our context, we pose the question to ourselves and non-Māori colleagues: "How do we identify and positively value Māori difference, and how does this difference register in a distinctive approach to psychotherapy?" In the light of Mãori identity differences and holistic concepts of mental health, a Māori psychotherapy would be relational, inclusive, contextual and spiritual. It would reaffirm links to family and extended family, ancestors, land, social justice, economic self-sufficiency and political emancipation. It would make use of indirect, allusive and metaphorical communication as well as being literal and grounded in clients' daily realities. It would seek to develop congruence between the client's inner world and their actual life circumstances. It would offer hope where there is despondency, strengthen purpose where there is aimlessness, and expand awareness to include a felt sense of all that has been lost and might be found. It would be pro Māori and positively value Māori relational concepts and Māori wisdom. 


\section{References}

Barlow, C. (1994). Tikkanga whakaaro: Key concepts in Māori culture. Auckland, Aotearoa New Zealand: Oxford University Press.

Durie, M. (1999). Mauri ora: The dynamics of Māori health. Auckland, Aotearoa New Zealand: Oxford University Press.

Hall, A. (2011, August). Cultural engagement in therapeutic practice. Paper presented at the 6th World Congress for Psychotherapy "World Dreaming”, Sydney, Australia.

Hall, A., \& Kohu-Morgan, H. (2011, August). Valuing “tuakana” (elder) “teina” (younger) roles in Indigenous research. Interactive paper presented at the 9th World Indigenous Peoples' Conference on Education “Living our Indigenous Roots”, Cusco, Peru.

Marsden, M. (2003). The woven universe: Selected writings of Revd. Māori Marsden. Otaki, Aotearoa New Zealand: Te Wananga o Raukawa. (Original work published 1992)

Morice, M. (2003). Towards a Māori psychotherapy: The therapeutic relationship and Māori concepts of relationship: A systematic literature review with case illustrations (Master's thesis). Auckland University of Technology, Auckland, Aotearoa New Zealand.

Morice, M. P., \& Woodard, W. (2011). Māori psychotherapy and the requirement to register under the Health Practitioners Competence Assurance Act 2003. In K. Tudor (Ed.), The turning tide: Pluralism and partnership in psychotherapy in Aotearoa New Zealand (pp. 69-76). Auckland, Aotearoa New Zealand: LC Publications.

Statistics New Zealand. (2006). Census of population and dwellings. Wellington, Aotearoa New Zealand: Author.

Tudor, K. (Ed.), (2011). The turning tide: Pluralism and partnership in psychotherapy in Aotearoa New Zealand. Auckland, Aotearoa New Zealand: LC Publications.

Waitangi Tribunal. (2011). The Treaty of Waitangi. Retrieved November 18, 2011, from http://www. waitangi-tribunal.govt.nz/treaty/

Wilmshurst, J. M., Anderson, A. J., Higham, T. F. G., \& Worthy, T. H. (2008). Dating the late prehistoric dispersal of Polynesians to New Zealand using the commensal Pacific rat. Proceedings of the National Academy of Sciences of the USA, 105(22), 7676-7680.

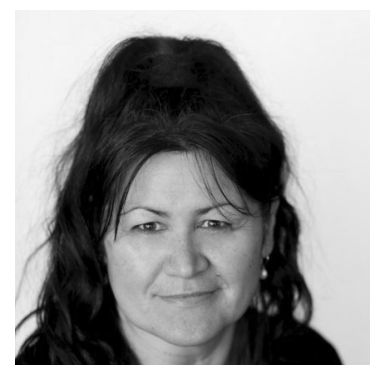

Alayne Mikahere-Hall (previously published as Alayne Hall) is kinship affiliated with Ngāti Whatua, Te Rarawa and Tainui. Alayne is a post-doctoral research fellow with Taupua Waiora Research Centre, Auckland University of Technology. She is the lead investigator on the Tūhono Māori research project, funded by the Health Research Council of New Zealand. Tūhono Māori is an investigation into a Māori understanding of secure attachment. Alayne engages with Indigenous methodologies and Kaupapa Māori methods and theory. She has an interest in developing evidence-based Māori and Indigenous therapeutic interventions to develop theories concerning complex trauma. Alayne is also an investigator on the E Tū Wāhine, E Tù Whānau study, aimed at reducing the harmful effects of violence against women and families and to break cycles of complex whakapapa trauma (inter-generational family trauma). She is a current member of the Health Quality and Safety Commission Child Youth Mortality 
Review Committee and Nga Pou Arawhenua Mortality Review Committee. Alayne is a Registered Psychotherapist, a member of the New Zealand Association of Psychotherapists (NZAP) and a founding member of Waka Oranga - National Collective of Māori Psychotherapy Practitioners (NCMPP). Contact details: alhall@aut.ac.nz.

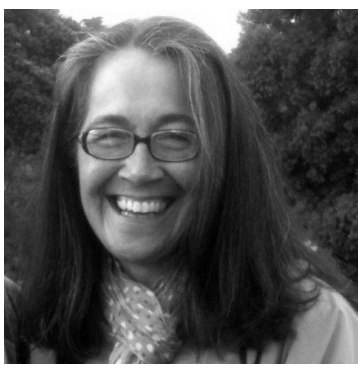

Margaret Poutu Morice is a 64-year-old Māori woman of Ngāti Porou descent through her mother and Ngāti Maniapoto and Scottish ancestry through her father. She is the sixth of their eight children and their youngest daughter. Being both big sister and little sister, she flourished in her position in the family. Caring for others has been a central task of Margaret's life, so marrying into a family of psychotherapists and then becoming one herself has felt like a calling and a natural progression. She is committed to her work and the values to which she and other practitioners in Waka Oranga aspire to, and this continues to define who she is and what she does. Contact details: margaretmorice@xtra.co.nz.

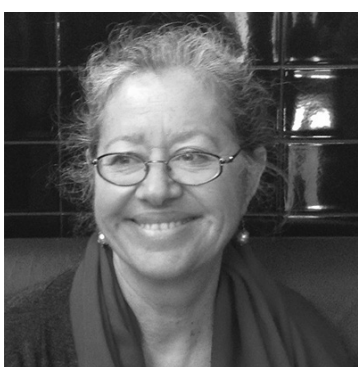

Cherry Pye (previously published as Cherry Wilson) (Ngāti Ranginui, Ngāi Te Rangi) resides on the beautiful Kapiti Coast in the wonderful town of Otaki. She and her husband Trevor have been there for almost seven years and have seven children and 11 precious mokopuna. She commutes twice weekly to the CBD in Wellington and is in a practice with lovely colleagues and friends at City Psychotherapy. Cherry also has a homebased part-time psychotherapy/counselling practice in Ōtaki. Cherry is a founding and active member of Waka Oranga, the collective of Māori psychotherapy practitioners of Aotearoa. She is a full member of NZAC and NZAP with an Advanced Clinical Practice Certificate. Cherry trained at Auckland University of Technology in the early 1990 s in Integrative Gestalt Therapy. After 20 years of being in the psychotherapy and counselling field she has become much more interested and attuned to how wairua facilitates movement/change in both the client and the therapist. Contact details: cherrympye@gmail.com. 